\title{
Developing a model for effective leadership in healthcare: a concept mapping approach
}

\author{
Charles William Hargett' \\ Joseph P Doty ${ }^{2}$ \\ Jennifer $\mathrm{N} \mathrm{Hauck}^{3}$ \\ Allison MB Webb ${ }^{4}$ \\ Steven $\mathrm{H} \mathrm{Cook}{ }^{5}$ \\ Nicholas E Tsipis ${ }^{4}$ \\ Julie A Neumann ${ }^{6}$ \\ Kathryn M Andolsek ${ }^{7}$ \\ Dean C Taylor 6 \\ 'Division of Pulmonary, Allergy, \\ and Critical Care Medicine, \\ Department of Medicine, ${ }^{2}$ Feagin \\ Leadership Program, ${ }^{3}$ Department of \\ Anesthesiology, ${ }^{4}$ School of Medicine, \\ ${ }^{5}$ Department of Neurosurgery, \\ ${ }^{6}$ Department of Orthopaedic Surgery, \\ ${ }^{7}$ Department of Community and \\ Family Medicine, Duke University \\ School of Medicine, Durham, NC, USA
}

Correspondence: Dean C Taylor Department of Orthopaedic Surgery, Duke University Medical Center, Box 3615, Durham, NC 27710, USA

$\mathrm{Tel}+\mid 9196681894$

Fax +19196816357

Email Dean.Taylor@Duke.edu
This article was published in the following Dove Press journal:

Journal of Healthcare Leadership

28 August 2017

Number of times this article has been viewed

Purpose: Despite increasing awareness of the importance of leadership in healthcare, our understanding of the competencies of effective leadership remains limited. We used a concept mapping approach (a blend of qualitative and quantitative analysis of group processes to produce a visual composite of the group's ideas) to identify stakeholders' mental model of effective healthcare leadership, clarifying the underlying structure and importance of leadership competencies.

Methods: Literature review, focus groups, and consensus meetings were used to derive a representative set of healthcare leadership competency statements. Study participants subsequently sorted and rank-ordered these statements based on their perceived importance in contributing to effective healthcare leadership in real-world settings. Hierarchical cluster analysis of individual sortings was used to develop a coherent model of effective leadership in healthcare.

Results: A diverse group of 92 faculty and trainees individually rank-sorted 33 leadership competency statements. The highest rated statements were "Acting with Personal Integrity", "Communicating Effectively", "Acting with Professional Ethical Values", "Pursuing Excellence”, "Building and Maintaining Relationships", and "Thinking Critically". Combining the results from hierarchical cluster analysis with our qualitative data led to a healthcare leadership model based on the core principle of Patient Centeredness and the core competencies of Integrity, Teamwork, Critical Thinking, Emotional Intelligence, and Selfless Service.

Conclusion: Using a mixed qualitative-quantitative approach, we developed a graphical representation of a shared leadership model derived in the healthcare setting. This model may enhance learning, teaching, and patient care in this important area, as well as guide future research.

Keywords: core competencies, healthcare leadership, medical education, mental models, mixed methods research

\section{Introduction}

Physicians must become effective healthcare leaders in order to influence the care of individual patients, the performance of diverse clinical teams, and the direction of major healthcare organizations and beyond. The importance of effective healthcare leadership is difficult to overestimate as leadership not only improves major clinical outcomes in patients, but also improves provider well-being by promoting workplace engagement and reducing burnout. ${ }^{1-5}$ We define the ability to influence as the foundation of our definition of healthcare leadership: Healthcare leadership is the ability to effectively and ethically influence others for the benefit of individual patients and populations.

Over the last ten years, we have created, implemented, and refined several undergraduate medical education (UME) and graduate medical education (GME) 
leadership development educational programs. We have found that medical students, residents (synonymous with junior registrar), and fellows (postgraduate trainees; synonymous with advanced specialist registrar) are exposed to little intentional education to prepare them for their current and future personal and professional leadership challenges. Importantly, from a developmental and educational perspective, omitting topics such as leadership in medical education "is a powerful, if unintended signal, that these issues are unimportant". ${ }^{6}$ Our programs are not designed to prepare individuals for specific leadership roles. Rather, they facilitate individuals' learning and development of leadership skills that will prepare them to influence many facets of life, including healthcare.

We have found that leadership models are extremely helpful for learners to grasp new concepts, make sense of lessons learned through their experiences, afford structure that facilitates lasting comprehension through reflection, and provide a basis for learner assessment and program evaluation. ${ }^{7}$ In the formative years of our programs, we used business leadership models as the foundation to teach leadership skills. Our review of other leadership development schools and professions (for example, the Wharton School of Business - University of Pennsylvania, the Fuqua Business School at Duke University, the United States Service Academies, and the Department of the Army) were helpful, yet they lacked emphasis on subtle aspects unique to healthcare leadership. We then looked for explicit healthcare leadership models and found that few existed. Further, none seemed to facilitate effective leadership learning in UME and GME.

Our inability to find an appropriate healthcare leadership model led us to create a leadership model specific to healthcare. This model needed to be based on competencies that were recognized as the most important attributes for effective healthcare leadership. The purpose of the paper is to present the research process that resulted in the Duke Healthcare Leadership Model, as shown in Figure 1.

\section{Methods}

The study was a mixed method study using a modified concept mapping approach to derive, prioritize, and thematically structure the fundamental competencies of healthcare leadership. Concept mapping is a mixed methods approach that combines qualitative group processes such as brainstorming and interpretive sorting with rigorous quantitative data analysis to produce a visual depiction of the composite thinking of the group. This process of structured conceptualization

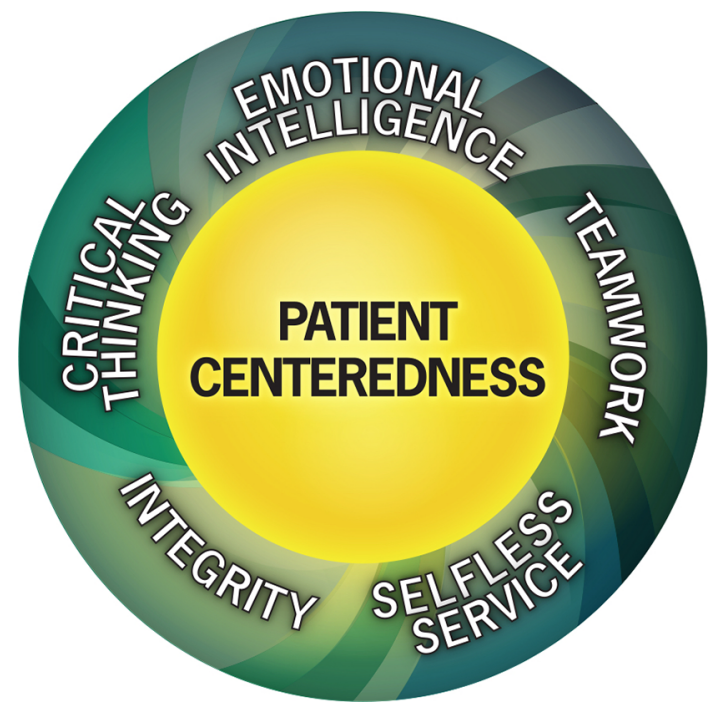

Figure I The Duke Healthcare Leadership Model. Note: C2017 Dean C. Taylor, MD. All rights reserved.

has been used to address complex issues in healthcare, and provides a framework that can guide action planning, program development or evaluation and measurement. ${ }^{8,9} \mathrm{We}$ used a comprehensive literature review and focus groups to develop a set of statements that described healthcare leadership competencies. Next, we implemented a card sorting task, followed by analysis and interpretation. Finally, we created and refined a graphical representation of healthcare leadership. These successive steps are illustrated in Figure 2 and will be explained in more detail in following sections. The study was approved by the Duke Health Institutional Review Board after it was determined to be exempt from full review. Participation was voluntary, and informed consent was not required.

\section{Literature review}

Building upon our prior meta-analysis exploring leadership curricula used to teach medical students, we performed an updated literature search and review of existing leadership models. ${ }^{10}$ Information gleaned was used to develop semistructured focus group interview questions, a list of common healthcare leadership attributes, and a script to be used in focus group discussions.

\section{Focus groups}

Participants were recruited to collect expert opinion on the leadership competencies required of a healthcare leader in any environment. Each focus group lasted approximately two hours, and was led by the same team of moderators. Moderators used the script developed from the semi-structured 

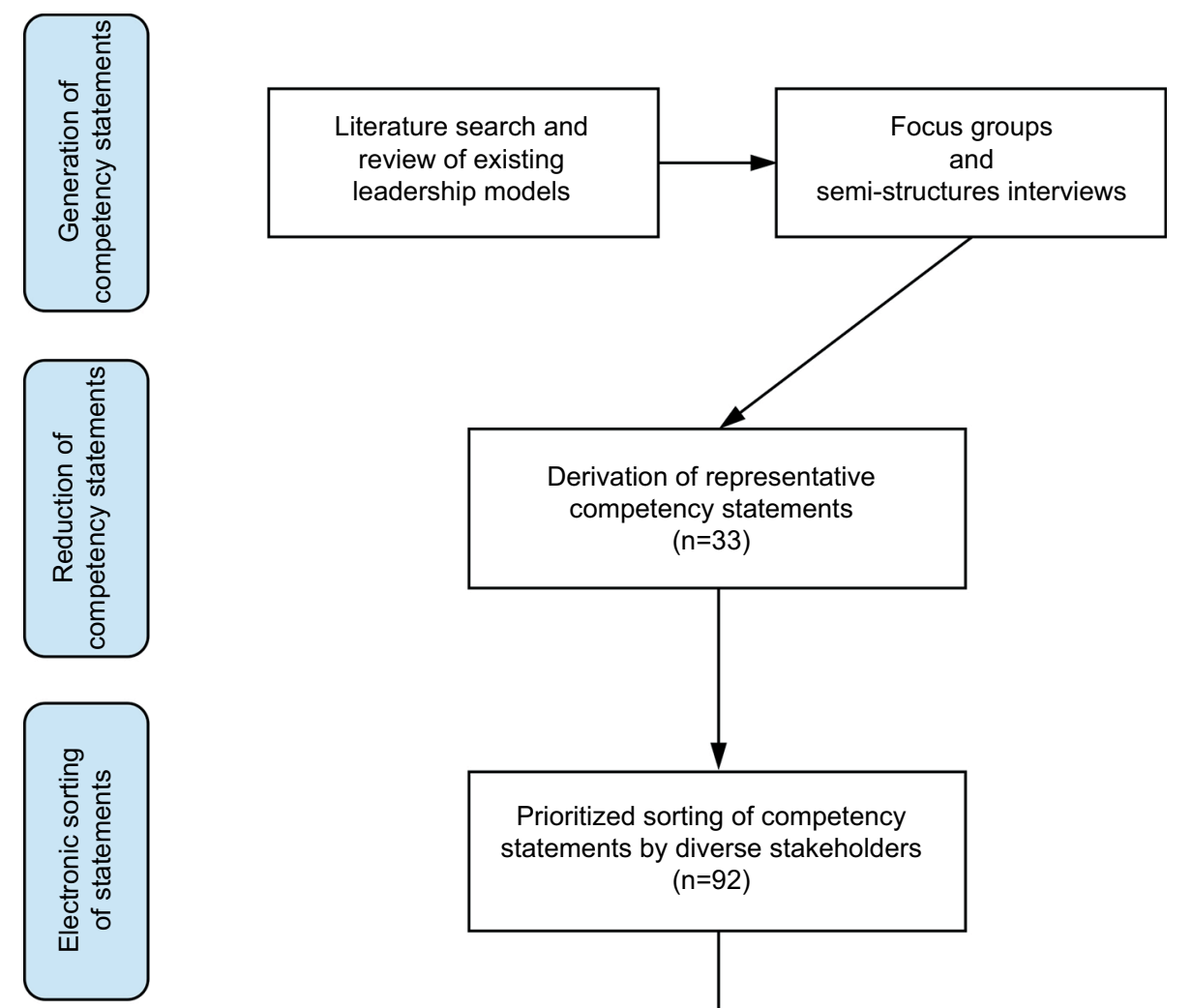

Derivation of representative competency statements $(n=33)$
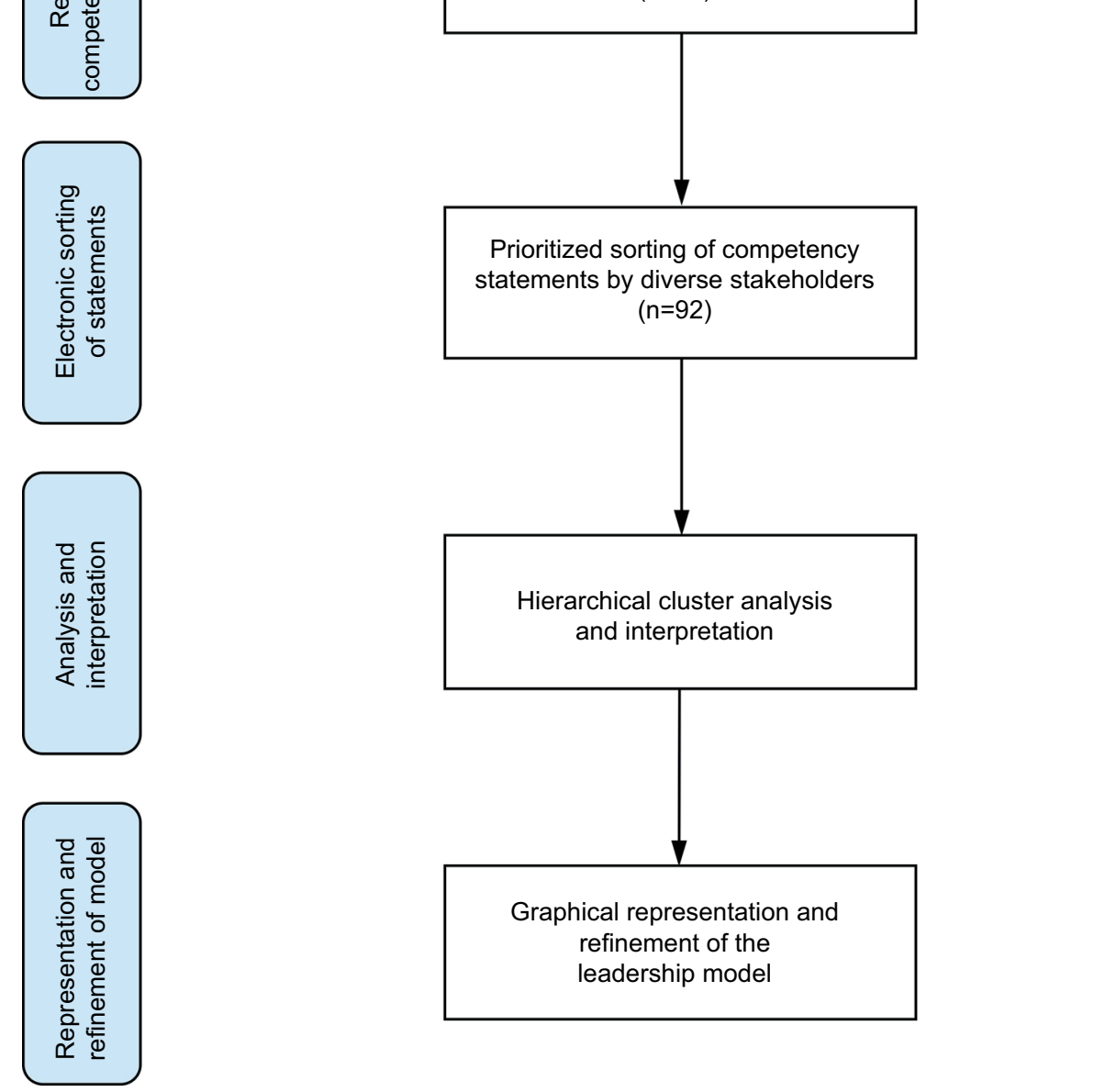

Figure 2 Sequence of steps in the concept mapping approach to derive, prioritize, and thematically structure the fundamental competencies of leadership in medicine.

focus group interview questions to lead the discussions. One of the moderators took notes of the comments from the group members and from subsequent debriefing sessions. The focus groups were also asked to critique the leadership attributes identified from the literature. Participants were asked to rank the top 10 attributes required of a healthcare medical leader. The focus group data were analyzed through constant comparison analysis by identifying common themes through saturation within each group and across groups. An initial set of competency statements was derived and further refined by eliminating duplication and targeting specifically for healthcare settings. The resulting competency statements formed the basis for the quantitative card sorting and cluster analysis.

\section{Card sorting task}

The sorting procedure was administered online with the open source program FlashQ. ${ }^{11}$ Following an introduction with instructions, participants were presented with the focus group leadership competency statements in random order and asked 
to sort them in order of importance based on their individual point of view. More specifically, participants were asked to rate the relative importance of each leadership attribute based on its value or importance in contributing to effective leadership performance in real-world clinical situations. During the sorting process, participants placed one unique statement in each box on a grid with a fixed quasi-normal distribution. Competency statements could be allocated to a ranking position ranging from +5 (most important) to -5 (least important). Respondents could change the placement of cards until the final positioning of all statements reflected their ranking of the statements relative to each other in importance. After completing the card sorting, participants were asked to provide their rationale for placing the competency statements at the extreme ends ( +5 or -5 columns) of the sorting grid. All responses were anonymous, though respondents could elect to enter demographic data, including sex, current role, and leadership experience.

\section{Hierarchical cluster analysis}

Demographic data and importance scores were calculated using descriptive statistics. All data were analyzed with JMP Pro 13.0 (SAS Institute Inc., Cary, NC, USA). Cluster analysis is a statistical technique to find similar groups of cases in a data set and is particularly useful in the development of a classification or conceptual scheme. Hierarchical cluster analysis (Ward's method, squared Euclidean distances) was used to classify leadership competency statements based on the similarity of individual sorting responses of each participant. Guided by the dendrogram and agglomeration schedule, investigators (CWH, JPD, DCT) determined the final number of clusters by consensus and based on the criterion that the clusters should reflect meaningful, distinct domains related to effective leadership in a healthcare setting.

\section{Mixed methods analysis}

We analyzed the quantitative data in conjunction with the qualitative data obtained from the focus group discussions and the statements provided by card sorting participants. This mixed methods analysis helped us define the primary healthcare leadership competency themes. Earlier versions of the model originated within our Feagin Leadership Program and the Leadership Education And Development (LEAD) Curriculum, which are internal initiatives within our UME and GME programs. The initial models were refined based on input and feedback obtained from multiple faculty, house staff, and residents over a three-year period.

\section{Results}

\section{Literature review}

The literature review found that healthcare leadership is a skill that must be $\mathrm{e}^{12-14}$ and can be $\mathrm{e}^{15-17}$ intentionally taught. Further, the literature review provided information on healthcare leadership attributes and content ${ }^{18-25}$ that we used to guide the discussion to the semi-structured focus group interview questions. Thirty-nine healthcare leadership attributes were identified and used to determine the competency statements in the focus groups.

\section{Focus groups}

Three focus groups were carried out with a total of 19 participants, many being clinical faculty with administrative or leadership roles. From the 39 healthcare leadership attributes identified through the literature review, the focus groups' work led to a set of 33 competency statements that represent important aspects of healthcare leadership (Supplementary material). These statements formed the basis for the card sorting task. Each one of the statements:

1. Described some of the fundamental knowledge, skills, or attitudes related to leadership (influencing others) in a healthcare setting

2. Represented the basic competencies that may be demonstrated by successful physician leaders, regardless of their work setting

3. Described the knowledge, skills, and attitudes that combine to enable residents and fellows to demonstrate behaviors that help assure effective leadership performance in real-world clinical situations

In addition to identifying the statements for our quantitative card sorting task, the focus groups also provided important qualitative data. All three focus groups emphasized that Patient Centeredness and Selfless Service are two competencies essential to effective healthcare leadership. Further, each focus group emphasized that Patient Centeredness was essential to any healthcare leadership model as this principle differentiated healthcare leadership from leadership in other fields.

\section{Card sorting task}

Approximately 200 faculty (attending physicians and nonphysician professionals) and learners (medical students, residents, and fellows) were recruited via email to participate in the card sorting exercise. Ninety-two participants responded (46 percent) ( 22 medical students, 29 physicians-in-training, 25 attending physicians, and 16 non-physician professionals). 
Sixty percent were men, and two-thirds reported prior formal leadership training. Table 1 presents a basic summary of the participants in the card sorting task. Table 2 summarizes the mean values for importance of the top competency statements.

\section{Hierarchical cluster analysis}

Through hierarchical cluster analysis, the competency statements fell into five domains. We labeled four of the domains based on the predominant themes of the competency statements in those domains: Integrity, Teamwork, Critical Thinking, and Emotional Intelligence. A fifth domain comprised a set of low-rated competency statements for which no unifying theme could be identified (Figure 3). Fundamental leadership domains with mean importance scores for each leadership competency statement are presented in Table 3.

\section{Mixed methods analysis}

Mixed methods analysis of the quantitative and qualitative data resulted in two additional competency themes for the healthcare leadership model. We used the qualitative input from the focus groups and the card sorting comments to separate Patient Centeredness and Selfless Service from the Emotional Intelligence domain (Figure 3). The focus group affirming that Patient Centeredness is a unique, defining component found in effective healthcare leaders was confirmed through feedback and experience we received when testing early versions of the model in leadership education settings. We concluded that Patient Centeredness is more than a competency for healthcare leadership; it is a core principle.

We also identified the highly rated statement of "Communicating Effectively" (originally clustered in the Integrity domain) as essential to each domain, and not a separate competency. Similarly, "Pursuing Excellence", although highly rated and part of the Critical Thinking domain, is a statement that is an aspirational goal and, as such, a part of each competency.

Finally, we modified the graphic representation of the model based on its use in teaching students, residents, and fellows, along with the feedback we received from these learners and faculty. The resulting model (Figure 1) features that the central core principle of Patient Centeredness is surrounded by the overlapping five core competencies. We recognize Emotional Intelligence ${ }^{26,27}$ as the core competency that holds the other competencies together, and therefore it is positioned as the "keystone" in the model; if Emotional Intelligence is removed, the model will crumble. Integrity and Selfless Service are intentionally positioned at the base of the model; although they may be difficult to teach, they are extremely important to effective healthcare leadership and must be recognized and emphasized as essential "foundational" core competencies. Critical Thinking and Teamwork are positioned as the "framework core competencies", holding the model together and overlapping with the other three competencies.

Table I Characteristics of participants in card sorting

\begin{tabular}{|c|c|c|c|c|c|}
\hline Characteristics & $\begin{array}{l}\text { Medical } \\
\text { students } \\
(n=22)\end{array}$ & $\begin{array}{l}\text { Physicians } \\
\text { in training } \\
(n=29)\end{array}$ & $\begin{array}{l}\text { Attending } \\
\text { physicians } \\
(n=25)\end{array}$ & $\begin{array}{l}\text { Non-MD } \\
\text { professionals } \\
(n=16)\end{array}$ & $\begin{array}{l}\text { Total } \\
(n=92)\end{array}$ \\
\hline \multicolumn{6}{|l|}{ Sex, no. (\%) } \\
\hline Female & $8(44 \%)$ & 14 (50\%) & $7(32 \%)$ & $4(29 \%)$ & $33(40 \%)$ \\
\hline Male & $10(56 \%)$ & 14 (50\%) & 15 (68\%) & 10 (7I\%) & $49(60 \%)$ \\
\hline \multicolumn{6}{|c|}{ Leadership training, no. (\%) } \\
\hline Prior formal training & $12(57 \%)$ & $15(54 \%)$ & $19(83 \%)$ & II (73\%) & 57 (66\%) \\
\hline
\end{tabular}

Note: Discrepancies in totals are due to incomplete responses as demographic questions were optional.

Table 2 Top competency statements ranked by mean (SD) importance score

\begin{tabular}{ll}
\hline Competency statements, mean ( \pm SD) & $\begin{array}{c}\text { Total } \\
(\mathbf{n = 9 2})\end{array}$ \\
\hline Acting with Personal Integrity - behaving in an open, honest, and trustworthy manner & $3.07( \pm 2.24)$ \\
Communicating Effectively - ability to communicate with patients and team; successfully navigating difficult conversations and & $2.98( \pm 1.8)$ \\
providing feedback & $1.98( \pm 2.27)$ \\
Acting with Professional Ethical Values - applying medical ethical principles to difficult situations & $1.2( \pm 2.75)$ \\
Pursuing Excellence - striving for excellence in all areas of personal, team, and organizational life & $1.15( \pm 2.17)$ \\
Building and Maintaining Relationships - listening to and supporting others, gaining trust, and showing understanding & $1.12( \pm 2.5)$ \\
\hline Thinking Critically - being able to think analytically and conceptually to evaluate and solve problems
\end{tabular}




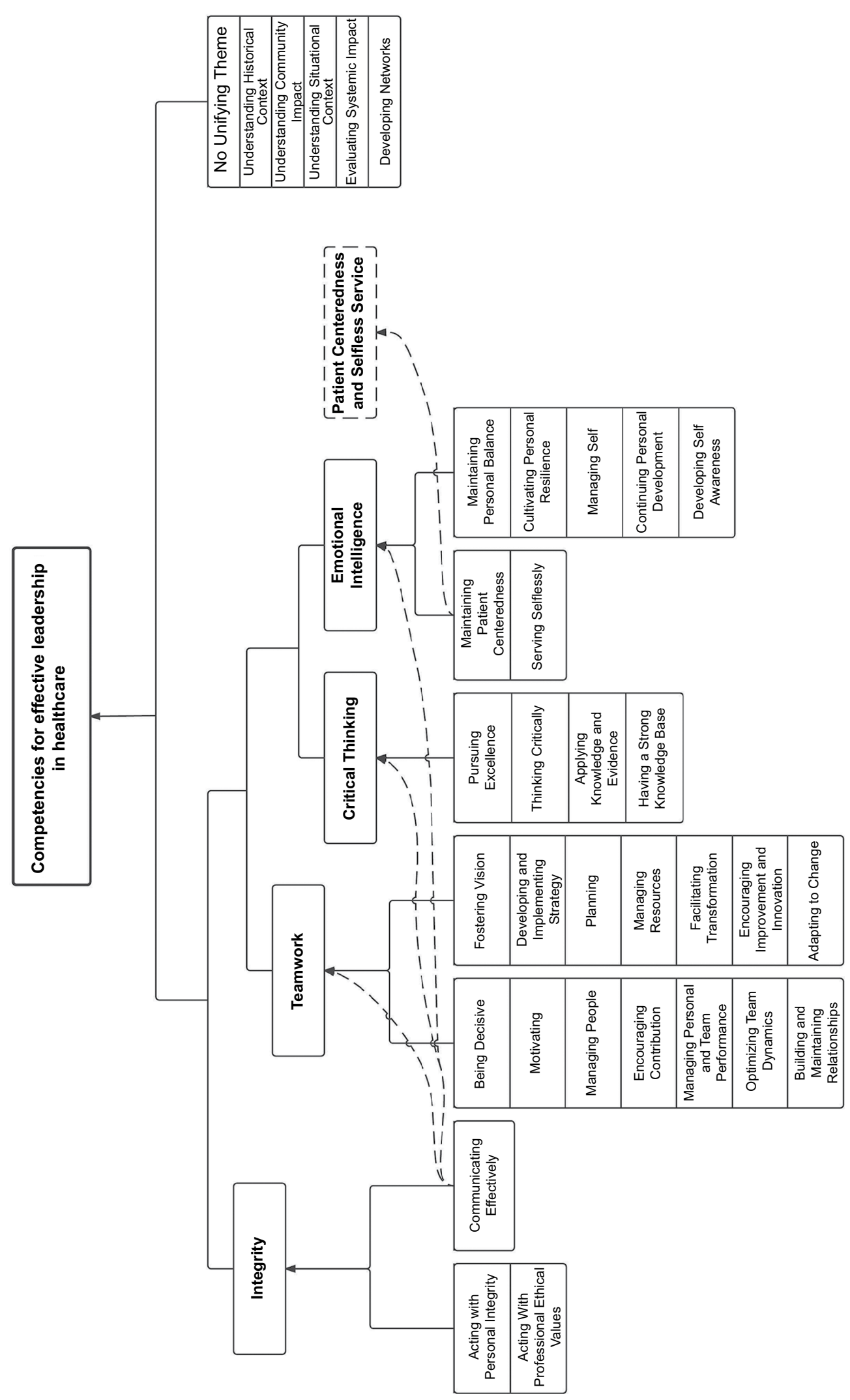


Table 3 Five fundamental competency themes in leadership in medicine with mean importance score for each competency statement

\begin{tabular}{|c|c|c|c|c|c|}
\hline Themes with statements, mean ( \pm SD) & $\begin{array}{l}\text { Medical students } \\
(n=22)\end{array}$ & $\begin{array}{l}\text { Physicians } \\
\text { in training } \\
(n=29)\end{array}$ & $\begin{array}{l}\text { Attending } \\
\text { physicians } \\
(\mathbf{n}=\mathbf{2 5})\end{array}$ & $\begin{array}{l}\text { Non-MD } \\
\text { professionals } \\
(n=16)\end{array}$ & Total $(n=92)$ \\
\hline \multicolumn{6}{|l|}{ Integrity } \\
\hline Acting with Personal Integrity & $2.86( \pm 2.5 \mathrm{I})$ & $2.24( \pm 2.52)$ & $3.56( \pm 1.85)$ & $4.06( \pm 1.18)$ & $3.07( \pm 2.24)$ \\
\hline Communicating Effectively & $2.77( \pm 2.09)$ & $3.59( \pm 1.78)$ & $2.76( \pm 1.64)$ & $2.5( \pm I .5 I)$ & $2.98( \pm 1.8)$ \\
\hline Acting with Professional Ethical Values & $1.36( \pm 2.48)$ & $1.21( \pm 2.21)$ & $2.28( \pm 1.97)$ & $3.75( \pm I .44)$ & $1.98( \pm 2.27)$ \\
\hline \multicolumn{6}{|l|}{ Critical Thinking } \\
\hline Pursuing Excellence & $1.41( \pm 2.5)$ & $0.83( \pm 2.9)$ & $1.16( \pm 3.1)$ & $1.63( \pm 2.36)$ & $1.2( \pm 2.75)$ \\
\hline Thinking Critically & $2.09( \pm 2.11)$ & $1.41( \pm 2.47)$ & $0.32( \pm 2.67)$ & $0.5( \pm 2.42)$ & $1.12( \pm 2.5)$ \\
\hline Having a Strong Knowledge Base & $0.09( \pm 3.29)$ & $-1.03( \pm 2.98)$ & $-2.36( \pm 2.94)$ & $0.56( \pm 2.58)$ & $-0.85( \pm 3.13)$ \\
\hline Applying Knowledge and Evidence & $-0.68( \pm 2.83)$ & $-0.62( \pm 2.44)$ & $-0.8( \pm 2.68)$ & $-0.69( \pm 2.77)$ & $-0.7( \pm 2.62)$ \\
\hline \multicolumn{6}{|l|}{ Selfless Service } \\
\hline Maintaining Patient Centeredness & $0.86( \pm 2.92)$ & $0.28( \pm 3.22)$ & $0.36( \pm 2.94)$ & $1.56( \pm 2.58)$ & $0.66( \pm 2.96)$ \\
\hline Serving Selflessly & $-0.45( \pm 3.43)$ & $-1( \pm 3.36)$ & $0.72( \pm 2.7)$ & $-0.56( \pm 2.7 \mathrm{I})$ & $-0.33( \pm 3.13)$ \\
\hline \multicolumn{6}{|l|}{ Emotional Intelligence } \\
\hline Developing Self-awareness & $0.18( \pm 2.84)$ & $-0.97( \pm \mathrm{I} .84)$ & $\mathrm{I} .08( \pm 2.77)$ & $0.13( \pm 3.05)$ & $0.05( \pm 2.66)$ \\
\hline Continuing Personal Development & $-0.45( \pm 2.32)$ & $-0.55( \pm 1.86)$ & $0.04( \pm 2.52)$ & $-0.88( \pm 2.03)$ & $-0.42( \pm 2.19)$ \\
\hline Managing Self & $-0.82( \pm 2.32)$ & $-0.03( \pm 2.5)$ & $-0.24( \pm 2.76)$ & $-0.25( \pm 2.21)$ & $-0.32( \pm 2.46)$ \\
\hline Cultivating Personal Resilience & $-0.27( \pm 2.12)$ & $-0.93( \pm 2.05)$ & $-0.84( \pm 2.48)$ & $-0.13( \pm 1.63)$ & $-0.61( \pm 2.12)$ \\
\hline Maintaining Personal Balance & $-1.09( \pm 3.04)$ & $-1.24( \pm 2.89)$ & $-0.88( \pm 2.76)$ & $0.38( \pm 2.45)$ & $-0.83( \pm 2.83)$ \\
\hline \multicolumn{6}{|l|}{ Teamwork } \\
\hline Being Decisive & $0.23( \pm 2.74)$ & $0.17( \pm 3.16)$ & $0.08( \pm 2.16)$ & $I( \pm I .86)$ & $0.3( \pm 2.59)$ \\
\hline Building And Maintaining Relationships & $1.68( \pm 1.96)$ & $1.17( \pm 2.11)$ & $0.88( \pm 2.5 \mathrm{I})$ & $0.81( \pm 2.07)$ & $1.15( \pm 2.17)$ \\
\hline Optimizing Team Dynamics & $0.59( \pm 3.11)$ & $1.55( \pm 1.96)$ & $0.24( \pm 1.54)$ & $0.44( \pm 2.58)$ & $0.77( \pm 2.33)$ \\
\hline Managing Personal and Team Performance & $0.27( \pm 1.96)$ & $0.34( \pm 2.21)$ & $0.44( \pm 1.66)$ & $0.31( \pm 2.44)$ & $0.35( \pm 2.02)$ \\
\hline Motivating & $1.05( \pm 2.19)$ & $0.86( \pm 2.22)$ & $1.24( \pm 2.13)$ & $0.44( \pm 2.99)$ & $0.93( \pm 2.31)$ \\
\hline Managing People & $-0.09( \pm 2.56)$ & $1.72( \pm 1.89)$ & $0.28( \pm 2.3)$ & $0.56( \pm 2.73)$ & $0.7( \pm 2.4)$ \\
\hline Encouraging Contribution & $0.27( \pm 2.69)$ & $0.45( \pm 1.86)$ & $0.32( \pm 2.48)$ & $-0.44( \pm 2.13)$ & $0.22( \pm 2.28)$ \\
\hline Fostering Vision & $-0.09( \pm 3.46)$ & $-0.1( \pm 2.91)$ & $0.16( \pm 3.05)$ & $-0.19( \pm 2.64)$ & $-0.04( \pm 3)$ \\
\hline Planning & $0.23( \pm 2.29)$ & $1.03( \pm 2.46)$ & $0.16( \pm 1.93)$ & $-1.81( \pm 2.69)$ & $0.11( \pm 2.48)$ \\
\hline Developing and Implementing Strategy & $-0.36( \pm I .7 I)$ & $-0.1( \pm 2.16)$ & $0.16( \pm 3.09)$ & $0.13( \pm 2.09)$ & $-0.05( \pm 2.32)$ \\
\hline Managing Resources & $-1.18( \pm 2.15)$ & $0.34( \pm 2.48)$ & $-0.96( \pm 2.28)$ & $-0.75( \pm 2.02)$ & $-0.57( \pm 2.33)$ \\
\hline Adapting to Change & $0.36( \pm 2.06)$ & $0.83( \pm 2.39)$ & $0.36( \pm 1.93)$ & $0( \pm 2.16)$ & $0.45( \pm 2.14)$ \\
\hline Encouraging Improvement and Innovation & $-0.09( \pm 1.8)$ & $0.55( \pm 2.1)$ & $-0.24( \pm 2.7)$ & $0.81( \pm 2.79)$ & $0.23( \pm 2.34)$ \\
\hline Facilitating Transformation & $-1.09( \pm 1.34)$ & $-0.76( \pm 2.46)$ & $-0.88( \pm 2.73)$ & $-1.19( \pm 1.97)$ & $-0.95( \pm 2.22)$ \\
\hline \multicolumn{6}{|l|}{ No Unifying Theme } \\
\hline Developing Networks & $-2.5( \pm 2.11)$ & $-1.86( \pm 2.52)$ & $-0.92( \pm 2.72)$ & $-2.13( \pm 2.31)$ & $-1.8( \pm 2.48)$ \\
\hline Evaluating Systemic Impact & $-0.68( \pm 1.78)$ & $-1.48( \pm 2.23)$ & $-1.04( \pm 1.72)$ & $-1.81( \pm 1.8)$ & $-1.23( \pm 1.93)$ \\
\hline Understanding Situational Context & $-1.05( \pm 2.28)$ & $-1.55( \pm 2.06)$ & $-1.52( \pm 2.06)$ & $-2.69( \pm 1.74)$ & $-1.62( \pm 2.1)$ \\
\hline Understanding Community Impact & $-1.82( \pm 2.67)$ & $-2.97( \pm 1.8)$ & $-3.04( \pm 1.62)$ & $-3.06( \pm 2.21)$ & $-2.73( \pm 2.1)$ \\
\hline Understanding Historical Context & $-3.59( \pm 1.79)$ & $-3.38( \pm I .72)$ & $-2.88( \pm 2.32)$ & $-3( \pm 2.34)$ & $-3.23( \pm 2.01)$ \\
\hline
\end{tabular}

\section{Discussion}

From curricular, pedagogical, and assessment perspectives, a model serves as the foundational starting point for learning and as an organizing framework for the developing leadership curricula. The model presented here addresses this need. We used a concept mapping approach to create a model specific to the needs of learning in healthcare leadership.

Our model was developed based on a comprehensive literature review, focus groups, concept mapping, and hierarchical clustering. Each of the 33 competency statements is an important concept of healthcare leadership. Our methods determined which statements were most important and which coalesced into themes. We began with an initial model that had been drafted within our UME and GME leadership programs (the Feagin Leadership Progam and LEAD Curriculum). Those initial drafts were further refined over a three-year period based on feedback we received from numerous people within our institution with varied levels of 
healthcare experience and training (faculty, fellows, residents, students, administrators, and non-physician educators). That input led to a model that has face validity, is well accepted, and can be used in pedagogical processes that help all of us learn to be better leaders.

Recent literature emphasizes the importance and need for the intentional, explicit promotion of leadership development curricula and training in medical education. ${ }^{28-31}$ Clearly, leadership development education should be intentional and not informal or implicit. The model presented here provides a framework for intentionally teaching leadership skills in healthcare education.

There continue to be efforts to appropriately characterize "content" 32 and define competencies. ${ }^{33}$ Sonnino argues for two dozen competencies, the most important of which are finances and economics, emerging issues and strategic planning, personal professional development, adaptive leadership, conflict management, time management, ethical considerations, and personal life balance. ${ }^{34}$ Seven of those eight align well with our model; we would argue that finances and economics are more managerial skills and context dependent. Further emphasizing the significance of leadership development in postgraduate medical education, in 2015 the Canadian residency CanMeds competency framework replaced their role of "manager" with that of "leader". 35

There are several limitations to our study. Foremost, model creation is not an exact science. Our mixed methods approach involves subjective interpretation of how to organize overlapping concepts. For example, communication could be considered a separate competency. Instead, we chose to include communication as essential for all core competencies - learning to communicate better enables one to be better at each healthcare leadership competency. Others' subjective assessments may have led to different interpretations.

This model is also derived from research done at a single institution, and as a result may not be generalizable to other settings. We do not suggest that ours is the only or best healthcare leadership model. It is offered as a model that others can use and refine for their own environments. The methods we describe can serve as a guide if others desire to create their own institutionally specific model. Nonetheless, this model has guided our teaching of skills and concepts that lead to improved competency in areas recognized as essential for effective, ethical healthcare leadership. It has subsequently led to an assessment of learners and an evaluation of our programs.
Models are most useful when validated. Preliminary validation of our model is complete. Our group is committed to re-validate the model in more diverse and larger healthcare settings. Our next steps involve developing, refining, and validating an evaluation instrument that assesses the competencies and core principle in the model. This work is underway through the Health Evaluation Assessment of Leadership. ${ }^{36}$

\section{Conclusion}

We designed a leadership model specific to healthcare using concept mapping. The research led to a model based on the core principle of Patient Centeredness and core competencies of Emotional Intelligence, Integrity, Selfless Service, Critical Thinking, and Teamwork. We have found this model useful for teaching leadership skills, and are currently designing a relevant evaluation instrument.

\section{Acknowledgments}

The authors thank members of the Feagin Leadership Program for their extensive backing of this project. The authors acknowledge all of the participants of the focus groups and other non-author members of their team including Prinny Anderson, MBA, Med; Jane Boswick-Caffery, MBA, MPH; Matthew Boyle, MD; Thomas Mullin, MD; and John Yerxa, MD. We also thank Saumil Chudgar, MD, MS, for feedback and editing work on this paper.

The authors acknowledge the assistance of Donald $\mathrm{T}$ Kirkendall, ELS, a contracted medical editor, for his assistance in preparing the manuscript for submission.

The views, opinions, and/or findings contained in this report are those of the author(s) and should not be construed as an official Department of the Army position, policy, or decision. Citation of trade names in this presentation does not constitute an official DA endorsement or approval of the use of such commercial items.

\section{Disclosure}

Allison MB Webb is currently a resident in the National Capital Consortium's program Combined Internal Medicine - Psychiatry Residency at Walter Reed National Military Medical Center, Bethesda, MD, USA. Nicholas E Tsipis is an Emergency Medicine Resident at Georgetown University Hospital/Washington Hospital Center, Washington DC, USA. Julie A Neumann is a sports medicine fellow at Kerlan-Jobe Orthopaedic Clinic. The authors report no conflicts of interest in this work. 


\section{References}

1. Cochran J, Kaplan GS, Nesse RE. Physician leadership in changing times. Healthc (Amst). 2014;2(1):19-21.

2. Ham C. Improving the performance of health services: the role of clinical leadership. Lancet. 2003;361(9373):1978-1980.

3. Majmudar A, Jain AK, Chaudry J, Schwartz RW. High-performance teams and the physician leader: an overview. J Surg Educ. 2010;67(4): 205-209.

4. Shanafelt TD, Gorringe G, Menaker R, et al. Impact of organizational leadership on physician burnout and satisfaction. Mayo Clin Proc. 2015;90(4): 432-440.

5. Shanafelt TD, Noseworthy JH. Executive leadership and physician well-being: nine organizational strategies to promote engagement and reduce burnout. Mayo Clin Proc. 2017;92(1):129-146.

6. Piper G, Gentile MC, Parks SD. Can Ethics Be Taught? Perspectives, Challenges and Approaches at the Harvard Business School. 2nd ed. Boston, MA: Harvard Business Review Press; 2007.

7. Snook S, Nohria N, Khurana R. The Handbook For Teaching Leadership: Knowing, Doing, And Being. Thousand Oaks, CA: Sage Publications; 2012.

8. Trochim W, Kane M. Concept mapping: an introduction to structured conceptualization in health care. Int J Qual Health Care. 2005;17(3):187-191.

9. Trochim W. An introduction to concept mapping for planning and evaluation. Eval Program Plann. 1989;12(1):1-16.

10. Webb AM, Tsipis NE, McClellan TR, et al. A first step toward understanding best practices in leadership training in undergraduate medical education: a systematic review. Acad Med. 2014;89(11):1563-1570.

11. Hackert C, Braehler G. FlashQ (version 1.0). 2014. Available from: http://www.hackert.biz/flashq/home/. Accessed April 20, 2017.

12. Arroliga AC, Huber C, Myers JD, Dieckert JP, Wesson D. Leadership in health care for the 21st century: challenges and opportunities. Am J Med. 2014;127(3):246-249.

13. Stoller JK. Commentary: recommendations and remaining questions for health care leadership training programs. Acad Med. 2013;88(1):12-15

14. Stoller JK. Help wanted: developing clinician leaders. Perspect Med Educ. 2014;3(3):233-237.

15. Careau E, Biba G, Brander R, et al. Health leadership education programs, best practices, and impact on learners' knowledge, skills, attitudes, and behaviors and system changes: a literature review. $J$ Healthc Leadersh. 2014;6:39-50.

16. Dannels SA, Yamagata H, McDade SA, et al. Evaluating a leadership program: a comparative, longitudinal study to assess the impact of the Executive Leadership in Academic Medicine (ELAM) Program for Women. Acad Med. 2008;83(5):488-495.

17. Day CS, Tabrizi S, Kramer J, Yule AC, Ahn BS; 2009-2010 Class of the AAOS Leadership Fellows Program. Effectiveness of the AAOS Leadership Fellows Program for Orthopaedic Surgeons. J Bone Joint Surg Am. 2010;92(16):2700-2708.
18. Blumenthal DM, Bernard K, Bohnen J, Bohmer R. Addressing the leadership gap in medicine: residents' need for systematic leadership development training. Acad Med. 2012;87(4):513-522.

19. Calhoun JG, Vincent ET, Baker GR, Butler PW, Sinioris ME, Chen SL. Competency identification and modeling in healthcare leadership. J Health Adm Educ. 2004;21(4):419-440.

20. Jones J, Hunter D. Consensus methods for medical and health services research. BMJ. 1995;311(7001):376-380.

21. McKenna MK, Gartland MP, Pugno PA. Development of physician leadership competencies: perceptions of physician leaders, physician educators and medical students. J Health Adm Educ. 2004;21(3):343-354.

22. NHS Institute for Innovation and Improvement. The Clinical Leadership Competency Framework. Coventry, England 2011. Available from: http://tinyurl.com/AMRCLeadershipFramework. Accessed March $27,2017$.

23. Rosenman ED, Shandro JR, Ilgen JS, Harper AL, Fernandez R. Leadership training in health care action teams: a systematic review. Acad Med. 2014;89(9):1295-1306.

24. Snyderman CH, Eibling DE, Johnson JT. The physician as team leader: new job skills are required. Acad Med. 2011;86(11):1348.

25. Taylor CA, Taylor JC, Stoller JK. Exploring leadership competencies in established and aspiring physician leaders: an interview-based study. J Gen Intern Med. 2008;23(6):748-754.

26. Bradberry T, Greaves J. Emotional Intelligence 2.0. San Diego, CA: Talent Smart; 2009.

27. Goleman D. Emotional Intelligence - Why It Can Matter More Than Iq. New York: Bantam Books; 2005.

28. Aggarwal R, Swanwick T. Clinical leadership development in post graduate medical education and training: policy, strategy and delivery in the UK National Health Service. J Healthc Leadersh. 2015;7:109-122.

29. Jardine D, Correa R, Schultz H, et al. The need for a leadership curriculum for residents. J Grad Med Educ. 2015;7(2):307-309.

30. Mintz LJ, Stoller JK. A systematic review of physician leadership and emotional intelligence. J Grad Med Educ. 2014;6(1):21-31.

31. Pololi P. Changing The Culture Of Academic Medicine-Perspective Of Women Faculty. Lebanon, NH: Dartmouth College Press; 2010.

32. Fraser TN, Blumenthal DM, Bernard K, Iyasere C. Assessment of leadership training needs of internal medicine residents at the Massachusetts General Hospital. Proc (Bayl Univ Med Cent). 2015;28(3):317-320.

33. Kiesewetter J, Schmidt-Huber M, Netzel J, Krohn AC, Angstwurm M, Fischer MR. [Training of leadership skills in medical education]. GMS Z Med Ausbild. 2013;30(4):Doc49. German [English abstract].

34. Sonnino RE. Health care leadership development and training: progress and pitfalls. $J$ Healthc Leadersh. 2016;8:19-29.

35. Royal College of Physicians and Surgeons of Canada. Leader. 2017. Available from: http://www.royalcollege.ca/rcsite/canmeds/framework/ canmeds-role-leader-e. Accessed March 27, 2017.

36. Murphy K, McManigle J, Wildman-Tobriner B, et al. Design, implementation, \& demographic differences of HEAL: a self-report healthcare leadership instrument. J Healthc Leadersh. 2016;8:1-9. 


\section{Supplementary material Competency statement definitions}

1. Acting with Personal Integrity - behaving in an open, honest, and trustworthy manner

2. Communicating Effectively - ability to communicate with patients and team; successfully navigating difficult conversations and providing feedback

3. Acting with Professional Ethical Values - applying medical ethical principles to difficult situations

4. Pursuing Excellence - striving for excellence in all areas of personal, team, and organizational life

5. Building And Maintaining Relationships - listening to and supporting others; gaining trust; and showing understanding

6. Thinking Critically - being able to think analytically and conceptually to evaluate and solve problems

7. Motivating - inspiring oneself and others to achieve goals

8. Optimizing Team Dynamics - understanding team members' roles, strengths, and weaknesses; influencing diverse talents to achieve common goals

9. Managing People - delegating, providing direction, and promoting equality and diversity

10. Maintaining Patient Centeredness - focusing on patients' best interests; working in partnership with patients; ensuring patient safety

11. Adapting To Change - flexibility, adapting to change readily, being the first to change when required

12. Managing Personal and Team Performance - the ability to assess successes and failures of oneself and team members and make adjustment as needed

13. Being Decisive - using values and evidence to act decisively, especially in difficult situations

14. Encouraging Improvement and Innovation - creating a climate of continuous quality improvement and identifying areas for growth

15. Encouraging Contribution - creating an environment where others have the opportunity to share their thoughts and ideas without fear of criticism

16. Planning - developing short-term and long-term plans to achieve personal, team, and organizational goals

Journal of Healthcare Leadership

\section{Publish your work in this journal}

The Journal of Healthcare Leadership is an international, peer-reviewed, open access journal focusing on leadership for the health profession. The journal is committed to the rapid publication of research focusing on but not limited to: Healthcare policy and law; Theoretical and practical aspects of healthcare delivery; Interactions between healthcare and society and evidence-based practices;
17. Developing Self-awareness - being aware of one's own values, principles, and assumptions

18. Fostering Vision - developing an organizational vision, communicating that vision, and embodying its principles

19. Developing and Implementing Strategy - integrating and aligning plans, resources, and people to achieve goals

20. Managing Self - organizing and self-regulating actions and emotions

21. Serving Selflessly - ability to put others' needs before one's own; demonstrating great concern for common good/other people

22. Continuing Personal Development - learning through continuous professional development and being open to feedback

23. Managing Resources - knowing what resources are available and using one's influence to ensure that resources are used efficiently and safely, reflecting the diversity of needs within given populations

24. Cultivating Personal Resilience - ability to cope with demanding situations

25. Applying Knowledge and Evidence - the ability to translate research and evidence-based practice in order to optimize outcomes

26. Maintaining Personal Balance - prioritizing activities to maintain mental and physical health

27. Having A Strong Knowledge Base - being an expert in a given field and demonstrating mastery of core knowledge

28. Facilitating Transformation - actively contributing to positive change

29. Evaluating Systemic Impact - measuring and evaluating outcomes; taking corrective action where necessary

30. Understanding Situational Context - seeking broader perspectives on problems; understanding community and stakeholders perspectives

31. Developing Networks - developing professional connections with stakeholders inside and outside the institution

32. Understanding Community Impact - having awareness that decisions about patient care impact population health

33. Understanding Historical Context - being aware of the history, culture, and traditions of the institution and including these in decision-making

\section{Dovepress}

Interdisciplinary decision-making; Philosophical and ethical issues; Hazard management; Research and opinion for health leadership; Leadership assessment. The manuscript management system is completely online and includes a very quick and fair peer-review system. Visit http://www.dovepress.com/ testimonials.php to read real quotes from published authors. 